\title{
Is the DHSS signing off?
}

\author{
NORMAN ELLIS
}

"We are determined to see that as many decisions as possible are taken at the local level." "The implications of this and other ministerial statements emphasising the dual themes of devolution and local autonomy seem to have fallen on deaf ears. This fundamental change of view, which occurred in May 1979, has been disbelieved or unnoticed in some quarters. This is not entirely accidental, since the interests of those who wish to reduce the impact of this policy are best served if the change is implemented by stealth. The change is evident in the contrast between the 173-page "Grey Book"2 and the seemingly endless flow of over a hundred circulars that poured out of the Health Departments during the 1974 reorganisation, and the seven-page circular on Health Service development structure and management $^{3}$ accompanied by a promise of little more to follow, issued in July 1980.

In 1974 the DHSS produced a blueprint for the Service which described in detail the structure of management and interprofessional relations. The complexity of the Grey Book's diagrams of management structure-appropriately described as exhibits-makes the plan of the Paris Metro look quite simple. The Government does not intend to repeat the experience of 1974 and will not be laying down central prescriptions for the Service. The DHSS no longer sees itself as all knowing and all wise, capable of establishing working relations between the various groups in the Service. Because the 1974 reorganisation weakened hospital administration the Department was irresistibly drawn into prescribing what should happen at the local level. For the 1982 reorganisation the Department will issue only the minimum of guidance. The process of reorganisation is now left to local initiative.

This emphasis on local autonomy was made in a recent ministerial statement outlining the considerably reduced function of the regional health authority. The Secretary of State, $\mathrm{Mr}$ Patrick Jenkin, said that he was determined to "ensure that regional health authorities too are slimmed down and their functions reduced. This is essential if we are to advance the greater local autonomy we seek."' Each new district health authority now has to decide for itself which managerial structure it should adopt. "Each DHA should have wide discretion in determining its management arrangements. Accordingly, the prescription of particular posts contained in previous circulars is now withdrawn." 3 The one remaining prescription is simply that there should be a district management team, consisting of a community physician, nurse, treasurer, administrator, consultant, and general practitioner, and that each authority should arrange its services into units of management, each with an administrator and a director of nursing services. The composition of the district management team will therefore remain unchanged.

What posts are at risk? The various hierarchies originally prescribed by the DHSS for the professions supplementary to medicine could well wither or disappear in many districts. For example, the existing area and district level posts in chiropody, dietetics, the remedial professions, speech therapy, radiography, and health education are probably at risk. No doubt each of these groups will argue that their particular circumstances merit a special circular from the centre. But such special pleading will

British Medical Association, BMA House, Tavistock Square, London WC1H 9JP

NORMAN ELLIS, MA, PHD, under secretary and senior industrial relations officer not overcome the Department's view that once it attempts to prescribe the position of one group it will inevitably have to do so for all other groups. In addition, the removal of the area tier should eliminate further posts in nursing and administration. Finally, the requirement that a $10 \%$ reduction in management costs should be achieved by 1985 will add impetus to the elimination of these hierarchies. There is, of course, another hierarchy that should wither: "the DHSS, on its part, is required by the Government to intervene less and to stand back more, encouraged by pressures to cut the size of its headquarters by at least $15 \%$ over the next three to four years." This statement was made by Sir Patrick Nairne, DHSS Permanent Secretary, in a speech to the Institute of Chartered Secretaries and Administrators on 15 October 1980.

Though the Government has emphasised that it does not want to see new hierarchies created in the new districts, the philosophy of local autonomy means that this could well happen. It is left to the DHAs to determine their own management arrangements, and the medical profession locally will no doubt want to influence their decisions. "It really is essential that the decisions on the structure of the management under the new district health authorities should be left to these authorities after they have been formed."

\section{Rule by local discretion}

The philosophy of local autonomy has ramifications well beyond the reduction of posts and hierarchies. On a wide range of matters local discretion will rule, and this trend is already apparent. A recent circular from the $\mathrm{DHSS}^{5}$ authorises health authorities to depart from national agreements on remuneration and conditions of service over a wide range of subjects without reference to the Department. This has already increased the scope for local discretion and reduced the participation of civil servants in the running of the Service. One matter delegated to local discretion by this particular circular that directly affects doctors is the national agreement on excess rent allowances.

But there are signs that a few wayward authorities are prejudging the pattern of devolution by exercising an improper degree of discretion on important matters affecting the medical profession. For example, some authorities have recently tried to depart from national agreements on study leave and removal expenses, despite firm guidance to the contrary from the DHSS. These authorities have lost no time in taking advantage of the devolution prescription, no doubt motivated by the need to cut the costs of medical care.

In the long term we can expect to see nearly 200 autonomous DHAs established. Within an overall cash limit each DHA will be free to exercise a wide measure of discretion in determining how this is spent. Thus the most important decisions on health care will in future be taken at the local level. These include local management arrangements, priorities for health care, and the crucial choices to be made concerning the competing demands of the now well-organised occupations in the Health Service, each articulating its own claim for an increased share of the limited resources available. As one seasoned BMA observer put it, "the choice between more doctoring or more portering has been left firmly on our doorstep."

There are important decisions to be taken during the next year as the new DHAs build their management structures. These decisions, though not irrevocable, will inevitably establish the 
might be saved before a final decision was taken on the issue of redundancies.

Several Council members spoke favourably about the loyalty of the staff and criticised the fact that they had not been consulted. Dr W J Appleyard is a member of the Finance and General Purposes Committee but he was not at the meeting that had made the recommendation. He proposed the referral back to the motion though he agreed that the sense had been changed by the reference to natural wastage and early retirement. The BMA should act as a good employer and if there had been proper consultations the savings might have been made. Dr John Ball pointed out that the Council had appointed the Finance and General Purposes Committee and sometimes it had to make unpleasant decisions. The Council would have to say what the alternative savings should be.

It was wrong, Mr A P J Ross said, for the BMA to insist on no medical redundancies in the NHS and then to talk about making its staff redundant. There could be savings in committee costs. If the Secretary reviewed the staffing structure and said that there was no surplus fat the Council would have to consider increasing the subscription.

Whatever the Treasurer suggested was unpopular, Dr R A Keable-Elliott said. The BMA had been living on its capital. The
Finance and General Purposes Committee had decided that the number of staff employed was too high; it was rubbish to say that everyone on the staff was sacrosanct. The Council had to be realistic, Dr W G A Riddle said. There might not be a need for redundancies but the recommendation must be passed on the understanding that Dr Havard would do everything he could to protect the staff. Dr Brian Lewis agreed: a computer had been installed, he said, and word processors bought to save staff but there had been no reductions. Comparable organisations were run with a smaller staff.

To try to meet the conflicting views that had been put forward $\mathrm{Mr}$ Grabham proposed to amend the recommendation to read: "That in order to achieve a saving of $£ 79000$ in 1981 the staff of the Association be reduced either by redundancies, natural wastage, early retirement (voluntary or compulsory) at the discretion of the Secretary in consultation with the committee unless after further discussions with the staff alternative savings can be identified which are found acceptable to the Finance and General Purposes Committee."

One or two speakers wanted to remove any reference to redundancies but the Treasurer pointed out that when someone was made redundant the Government paid $41 \%$ of the bill. Dr Havard said that he thought the money could be saved in other ways; meanwhile the staff would have the threat of redundancies hanging over them. Dr Appleyard's motion to refer the recommendation back was lost and Mr Grabham's amended motion was carried by a substantial majority.

\section{Future BMA meetings}

1981 ARM, Brighton, 29 June to 2 July Clinical Meeting, San Diego, California, 19 to 22 October

1982 ARM, London, 5 to 9 July Annual Scientific Meeting, Worcester, 9 to 11 September

1983 ARM, Dundee, 27 June to 1 July

Annual Scientific Meeting, Cambridge, 1 to 3 September

1984 ARM, Manchester, July

\section{Is the DHSS signing off?-continued}

framework of health care in each locality. The danger is that these decisions may be taken speedily and without regard for the DHSS's advice that DHAs should "avoid full-time posts at district level or below in any discipline or function unless they are sure that there is work to warrant them." 3

\section{"High risk" policy?}

The 1974 reorganisation reflected Whitehall's concern to prescribe standardised health care across the country. Central administrators treated health care as a commodity to be packaged and allotted in equal proportions like social security and unemployment benefit. And they relied on a watertight framework of standardised hierarchies and job descriptions to achieve this.

A senior civil servant has described the policy of delegation and autonomy as "high risk" because it means more local responsibility and initiative than has ever been expected or shown before and requires considerable local management talent to carry it through successfully.

From the medical profession's point of view a heavy new responsibility will be placed on the new medical advisory machinery ( $p 239$ ) and on the local organisation of the BMA. The prospect of 200 autonomous new health authorities, each evolving its own package of policies, means that there will be a wide range or issues that transcend particular crafts on which the whole profession will need to take a view. I suggested in a previous article ${ }^{6}$ that the BMA division is the obvious machinery for formulating and presenting the profession's view. [This article was prepared before the report on medical advisory machinery by the Chief Medical Officer's working group (p 239) had been published.-ED]

The craft committees will undoubtedly continue to service their various branches of the profession at the local level in the newly developed service, fulfilling functions analogous to those of the central craft committees. But it is on these other, wider issues, most of which will arise from a DHA's freedom to spend its own budget, that the medical profession will need to be united, active and vigilant.

\section{References \\ ${ }^{1}$ Department of Health and Social Security. Patients first. London: HMSO, 1979. \\ 2 Department of Health and Social Security. Management arrangements for the reorganised National Health Service. London: HMSO, 1972. \\ ${ }^{3}$ Department of Health and Social Security. Health Service development: structure and management. HC(80)8. London: DHSS, 1980 \\ 4 Anonymous. Slimming down RHAs. Br Med f $1981 ; 282: 247$. \\ 5 Department of Health and Social Security. Delegation of routine depart- mental variations and directions. $\mathrm{PM}(80) 35$. London: DHSS, 1980. \\ - Ellis N. Is the BMA division really necessary ? Br Med f 1980;280:1151-2.}

\section{Medical advice to the NHS-continued}

whichever body elected him and should keep it informed and consult with it as occasion demands.

Doctors should remember that the medical members of health authorities do not represent doctors working in the district and are not sitting on the authority to give formal medical advice. They are members of the health authority for their own personal qualities and to see that the appropriate medical advice is obtained through the channels described in the working party's report-namely, the clinical DMT members elected by and responsible to their colleagues.

NHS reorganisation mark II has given us another opportunity to look at how medical advice should be given to health authorities. In my view the working group's report outlines a simplified adaptable way for the profession to give advice at district level with a minimum of delay and little extra commitment for the practising doctor. The Department of Health has asked for views on the proposals by the end of March. The profession should discuss them thoroughly so as to ensure that in 1982 the NHS has a medical advisory structure in which doctors have confidence and which health authorities respect. 